\section{HYDROBIOLOGY \\ New Committee}

The Institute of Biology, following the findings of a working party on the role of the biologist in the management of water resources (see Biologist, 18, 59; 1971), has set up a Standing Committee on Biologists in the Water Industry which will advise the council of the institute on the representation of the views of biologists working in these fields. The committee will further advise biologists on the part they can play in water management, the type of training best suited to the job and will hope to provide the stimulus for ensuring that the necessary applied research and development is undertaken. Furthermore, it is hoped that the committee will be able to produce a register of hydrobiologists working in Britain. Interested biologists are asked to contact Dr C. M. R. Pastakia, Briant \& Harman, 16 Southwark Street, London SE1.

but this seemed unlikely. With reference to sucrose, Dr Shaper suggested that this is not a primary factor, but it acts synergistically with increased serum cholesterol and triglyceride concentrations.

Dr G. A. Gresham (University of Cambridge) emphasized that atherosclerosis is a human disease, and that attempts to reproduce it in experimental animals resulted in the development of only early facets of the disease process. Dr Gresham described a sequence of changes from the early fatty streak, through the development of a fibrous plaque to the complicated fully developed lesion. Early fatty streaks had been found in the large vessels of stillborn babies so that it is possible that the development of the disease is a lifelong process.

Professor P. Harris (Institute of Cardiology, London) gave a brief account of the structure of the myocardium as revealed by light and electron microscopy, and discussed the way in which energy, produced by the hydrolysis of ATP, is linked with the action potential, and the movement of sodium ions into the cells.

Dr M. C. Stone (Leigh Infirmary, Lancashire) discussed the role of diet in the management of hyperlipoproteinaemias. $\mathrm{He}$ and his collaborators have developed a simple method for studying the serum lipoprotein pattern by a combination of membrane filtration and nephelometry. Some types of hyperlipoproteinaemia, which may be indicative of a susceptibility to heart disease, have been successfully treated by diets containing $50 \mathrm{~g}$ of fat and $200 \mathrm{mg}$ of cholesterol. A substantial proportion of the fat which is given is polyunsaturated.

Professor F. Fidanza (Istituto Scienza Alimentazione, Perugia) described the epidemiological evidence for the fat theory of the aetiology of heart disease. Published records show a correlation between dietary fat and the incidence of arteriosclerosis. No such correlation is found in some peoples, such as the Masai and the Alaskan eskimos, and they are probably genetically adapted to such a diet. Professor Fidanza said that prospective epidemiological studies could give information that could be applied to individuals. $\mathrm{He}$ then discussed his own study on men aged 40 to 59 which had shown a significant correlation between the serum cholesterol concentration and the incidence of coronary heart disease, whereas energy consumption and the percentage of energy derived from protein or from fats showed no such correlation. There was, however, a variation from 3 to 29 in the percentage of energy derived from saturated fatty acids, and a high proportion was significantly correlated with coronary heart disease.

Dr A. J. Vergroesen (Unilever, Vlaardingen) has found that lauric and myristic acids increase the serum cholesterol concentration more than oleic acid, but that oleic acid acts synergistically with dietary cholesterol to produce high serum concentrations.

Professor J. Yudkin (Queen Elizabeth College, London) said that epidemiological evidence must be substantiated by experiments with animals and ulti- mately with humans. $\mathrm{He}$ has found that sucrose diets produce changes in lipid metabolism and platelet stickiness in man and animals which would indicate that sucrose is a dietary factor in heart disease.

Professor H. Keen (Guy's Hospital Medical School, London) presented data showing the fairly high incidence of undiagnosed diabetes in a population study in Bedford. He discussed the relationship between diabetes and atherosclerosis in Western countries. The poor correlation found in Japan was of interest especially in view of the changes in diet now occurring there.

Dr Margaret D. Crawford (London School of Hygiene and Tropical Medicine, London) discussed the hardness of water and cardiovascular disease. A higher incidence of all forms of heart disease is found in areas where the rainfall is high and the water soft. Hardening the water supply can reduce deaths from cardiovascular disease. In soft water areas, there is more disease of the arteries, and it may be that the electrolyte balance in heart muscle is affected. Dr Crawford also pointed out that the trace elements chromium, vanadium and selenium have a protective effect probably by reason of their effects on lipid metabolism, whereas cobalt and lead are deleterious.

After discussing previous work that had shown that suitably motivated individuals will accept changes in diet, Professor M. J. Karvonen (Institute of Occupational Health, Helsinki) presented results of a study in Helsinki into the effect of changes on the ratio of dietary polyunsaturated to saturated fatty acids on serum cholesterol.

\title{
Chick Red Cells make RNA
}

IN Nature New Biology next Wednesday (August 2) Madgwick, Maclean and Baynes report a set of quite simple and straightforward experiments which lead them to the conclusion that cbicken erythrocytes actively synthesize RNA; these nucleated red blood cells are not apparently as metabolically inert as biologists have assumed them to be.

Madgwick et al. incubated either washed chick erythrocytes or unwashed whole blood collected in heparin with one or other of three labels, ${ }^{3} \mathrm{H}$-uridine, ${ }^{3} \mathrm{H}$-adenine and ${ }^{3} \mathrm{H}$-thymidine. The last label was not incorpcrated to any significant extent which indicates, as expected, that the erythrocytes do not make much DNA. By contrast, both ${ }^{3} \mathrm{H}$-uridine and ${ }^{3} \mathrm{H}$-adenine are incorporated into a TCA precipitable material by a reaction that is sensitive to inhibition by actinomycin D.

The results of a variety of tests indicate that these two labels are being incorporated into RNA, and microscopic examination of stained smears indicates that the incorporation is not restricted to reticulocytes. The nature and role of the RNA made in these circulating and mature chick erythrocytes have yet to be elucidated, but it is not without significance that in some experiments the inhibition of RNA synthesis by actinomycin $D$ was accompanied by an inhibition of incorporation of ${ }^{3} \mathrm{H}$-leucine.

The life span of chick red blood cells in the circulation is about 28 days, much shorter than the life span of amphibian red cells, which is measured in hundreds of days, and this may explain why chick but not amphibian erythrocytes synthesize RNA; the chick cells may simply be comparatively immature. In any event, as Madgwick and his colleagues comment, anybody using nucleated erythrocytes to study the reactivation of nuclear metabolism would be well adyised to use amphibian rather than chicken red cells. 